\title{
Role of Fibrin Sealants in Liver Surgery
}

\author{
Marieke T. de Boer ${ }^{\mathrm{a}}$ Elizabeth A. Boonstra ${ }^{\mathrm{a}}$ Ton Lisman ${ }^{\mathrm{b}}$ Robert J. Porte ${ }^{\mathrm{a}}$ \\ ${ }^{a}$ Division of Hepatobiliary Surgery and Liver Transplantation, and b Surgical Research Laboratory, Department of \\ Surgery, University Medical Center Groningen, University of Groningen, Groningen, The Netherlands
}

\section{Key Words}

Fibrin sealant $\cdot$ Hemostasis $\cdot$ Bile leakage $\cdot$ Liver resection

\begin{abstract}
Background: Fibrin sealants are widely used in liver surgery. The aim of this article is to review the literature on evidence of hemostatic and biliostatic capacities of different fibrin sealants in liver surgery. Methods: In PubMed, a literature search was done with the search terms 'fibrin sealant' or 'fibrin glue' combined with 'liver resection' or 'bile leakage'. Thirteen comparative fibrin sealant studies were selected. Results: In general, these studies have shown a reduced time to hemostasis when fibrin sealants were used. So far, only a few studies have been published that have focused on postoperative resection surface-related complications. There is no strong evidence that fibrin sealants reduce the incidence of bile leakage after liver resection. Important new evidence shows that bile contains profibrinolytic activity that causes lysis of the clot formed by the fibrin sealant at least in vitro. Conclusions: Fibrin sealants can be effective as an adjunct to achieve hemostasis during liver resections. However, considering lack of evidence on the efficacy of fibrin sealants in reducing postoperative resection surface-related complications, routine use of fibrin sealants in liver surgery cannot be recommended.

Copyright $\odot 2012$ S. Karger AG, Basel
\end{abstract}

\section{Introduction}

Advances in surgical techniques and patient care have led to improvement in outcome after liver resections [1, 2]. Despite these improvements, intraoperative bleeding from the resection plane of the liver and postoperative resection surface-related complications like bleeding, bile leakage and abscess formation remain a major problem [2-4]. Apparently, conventional surgical techniques cannot completely eradicate these complications. Therefore, covering the liver resection surface with a product that can seal both blood vessels and biliary radicals is an interesting concept. For this reason, fibrin sealants are widely used in liver surgery [5-7] despite scarce scientific evidence on the clinical effectiveness of these products [8, 9]. The aim of this article is to review the literature on evidence of hemostatic and biliostatic capacities of different fibrin sealants in liver surgery.

\section{Methods}

In PubMed, a literature search was done with the search terms 'fibrin sealant' or 'fibrin glue' combined with 'liver resection' or 'bile leakage'. Clinical studies were selected that compared fibrin sealants with control treatment. Controls were either no treatment or treatment with another type of topical hemostatic agent

\section{KARGER}

Fax +41613061234 E-Mail karger@karger.ch www.karger.com
Marieke T. de Boer, MD

Department of Hepato-Pancreato-Biliary Surgery and Liver Transplantation

University Medical Center Groningen

PO Box 30.001, NL-9700 RB Groningen (The Netherlands)

Tel. +31 50361 2896, E-Mail m.t.de.boer@umcg.nl 
or another type of fibrin sealant. Studies were selected that were published in English and focused on hemostatic or biliostatic end points. In total, 163 titles were left for abstract screening. Twelve clinical comparative studies were recognized; after checking cross-references, one more comparative study was recognized.

\section{Different Types of Sealants}

Fibrin sealants are a group of topical hemostatic products that mimic the final stages of the blood coagulation process (fig. 1). Fibrin sealants are two-component products, containing thrombin and fibrinogen. When mixed together during application of the sealants, thrombin cleaves the fibrinogen to monomers, which polymerize to form a fibrin gel $[9,10]$. Fibrin sealants can come in twocomponent vials to form a glue $\left(\right.$ Tissucol ${ }^{\circledR}$, Tisseel ${ }^{\circledR}$, Quixil ${ }^{\circledR}$, Evicel ${ }^{\circledR}$, Crosseal $^{\circledR}$, Vivostat ${ }^{\circledR}$, Beriplast ${ }^{\circledR}$, Bio$\mathrm{col}^{\circledR}$, Bolheal ${ }^{\circledR}$, Hemaseel ${ }^{\circledR}$ ), but they can also be carried on a matrix, the so-called carrier-bound fibrin sealants. Carrier-bound sealants are available in a solid form, consisting of a collagen fleece coated with a dry form of fibrinogen and thrombin (Tachosil ${ }^{\circledR}$, Tachocomb ${ }^{\circledR}$ ), and in liquid form containing thrombin and gelatin (Floseal ${ }^{\circledR}$ ) or thrombin and collagen (Costasis ${ }^{\circledR}$ ).

While the basic components of most fibrin sealants are similar, different formulations and varying concentrations of the key components may cause differences between the products in fibrin clot formation. Apart from the concentration of thrombin and fibrinogen, the presence of antifibrinolytics, calcium concentration, the presence of other plasma proteins, ionic strength and temperature all affect the speed of clot formation and stability and adhesive strength of the clot that is formed [9, 11-13].

\section{Clinical Studies on Fibrin Sealants in Liver Surgery}

Kohno et al. [14] were the first to publish a randomized study on fibrin sealant in liver resection. The aim of the study was to compare clinical efficacy of two hemostatic agents on hemostasis and postoperative complications. They compared 31 patients receiving fibrin sealant glue (Beriplast) with 31 patients receiving a microcrystalline collagen powder (Avitene ${ }^{\circledR}$ ) in elective liver resection. They showed equal hemostatic effects in both groups. A dry cut surface of the liver was obtained during surgery in $27(87 \%)$ patients in the fibrin glue group and in 25 $(81 \%)$ in the collagen group. Postoperative bleeding was

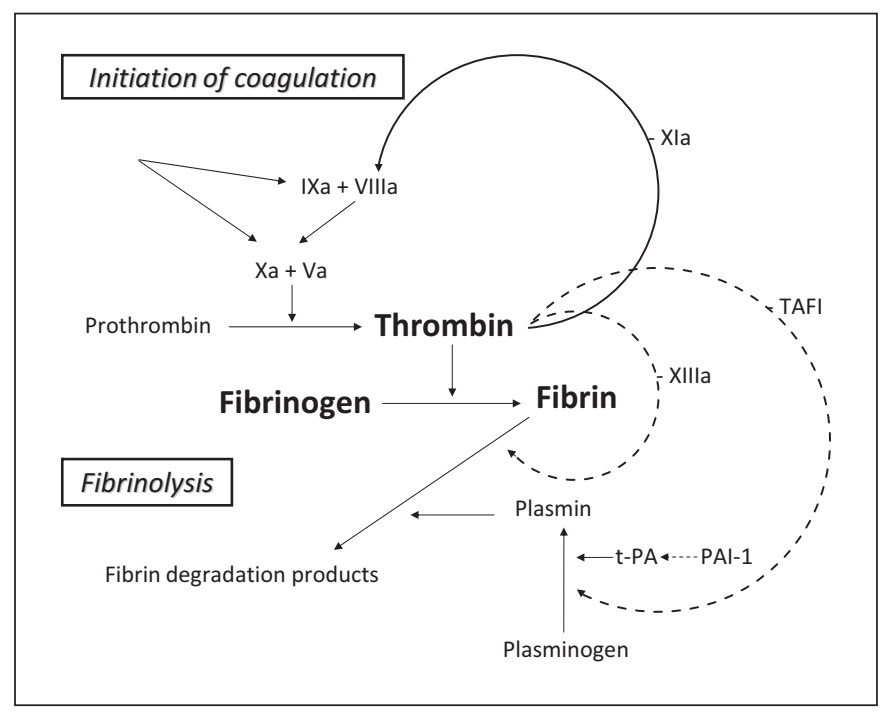

Fig. 1. General working mechanism of fibrin sealants (components fibrinogen and thrombin) mimicking blood coagulation process. TAFI $=$ Thrombin-activatable fibrinolysis inhibitor; dashed lines = inhibiting effect; continuous lines = stimulating effect.

$6 \%$ in both groups, and there were no differences in morbidity and mortality. Considering the fact that there were fewer patients with bile leakage from the resection surface of the liver in the fibrin sealant group ( 0 patients vs. 2 patients in the collagen group, n.s.), they concluded that fibrin sealants were more reliable than microcrystalline collagen powder in the postoperative course [14].

Noun et al. [15] randomized 82 patients comparing fibrin sealant glue (Biocol, 38 patients) on the liver resection plane with conventional hemostasis of the resection surface in 44 patients. The aim of the study was to evaluate the efficacy and safety of fibrin sealant after its application to the liver resection surface. A dry cut surface of the liver was obtained in $97 \%$ in the fibrin sealant group versus $81 \%$ in the conventional group $(\mathrm{p}=0.016)$. There was no difference between the groups in the time to reach complete hemostasis. There was also no difference in the amount of perioperative blood transfusions. Postoperative morbidity and mortality in both groups were equal, although the mean total fluid drainage during the first 3 days and the bilirubin concentration in this fluid were significantly lower in the group with fibrin glue. They concluded that fibrin glue application to the hepatic stump after hepatic resection provides effective sealing [15].

A reduction in postoperative drain fluid production when fibrin sealants were applied on the resection plane 
of the liver was confirmed in a pilot study by Eder et al. [16]. A fibrin sealant group (Tissucol or Tachocomb, 13 patients) was compared with a group of patients who did not receive fibrin sealant, only conventional hemostasis (12 patients). This was a small comparative non-randomized study, although both groups appeared to be comparable considering age, sex and extent of surgical resection. Drainage volumes were determined in 4 -hour intervals through the first $24 \mathrm{~h}$ after surgery, showing favorable results in the fibrin sealant group [16].

Another randomized study showed a significant reduction in the amount of hemoglobin in postoperative drain production when fibrin sealant was used [17]. The use of fibrin sealant on the resection surface (Beriplast, 20 patients) was compared with conventional hemostasis of the resection surface in 20 patients in liver resection. The focus of the study was on the efficacy of fibrin sealant in reducing postoperative bleeding complications. The conclusion of this study was that fibrin sealant is useful in control of postoperative bleeding after liver resection [17].

More recently, Chapman et al. [18] compared the hemostatic performance of a composite of bovine microfibrillar collagen and bovine thrombin mixed with autologous plasma (Costasis, 38 patients) with the application of a collagen sponge (Instat ${ }^{\circledR}, 29$ patients) on the hepatic resection margin, in a randomized fashion. There were no differences regarding transfusion requirements. The investigators did see a significant difference in the time to achieve hemostasis, favoring the fibrin sealant group. In all 38 patients in the fibrin sealant group, complete hemostasis was achieved within 10 min compared with only $69 \%$ of control subjects. The median time to controlled bleeding was significantly longer for control subjects [18].

A study with a similar primary end point was performed by Schwartz et al. [19] comparing the use of a fibrin sealant glue (Crosseal, 58 patients) with standard topical hemostatic agents (Actifoam ${ }^{\circledR}$, Avitene, Gelfoam ${ }^{\circledR}$, Oxycel ${ }^{\circledR}$, Surgicel ${ }^{\circledR}$, Surgicel Nu-Knit ${ }^{\circledR}$, and Thrombinar ${ }^{\circledR}$, total 63 patients). Application of fibrin sealant resulted in a statistically significant improvement in time to hemostasis compared to application of standard topical hemostatic agents. Secondary end point of this study was focused on postoperative resection surface-related complications. Postoperative complications (defined as reoperation for any reason, a diagnosis of abdominal fluid collections or bilious drainage for at least one day) were significantly lower in the fibrin sealant group (17.2\%) compared to the control group (36\%). The percentage of patients with abdominal collections was significantly lower in the Crosseal group than in the control group (3.4 vs. 14.3\%). In this publication, there were no further details of these results. The authors stated that there were no significant differences in intraoperative blood loss, duration of postoperative bilious drainage, percentage of patients with bile loss, volume of drainage fluid, and duration of drainage, though differences favored the fibrin sealant group [19].

Frilling et al. [20] reported on the hemostatic efficacy of a solid matrix fibrin sealant (Tachosil, 59 patients) versus argon beam coagulation of the resection surface (62 patients). This randomized multicenter study showed that fibrin sealant was superior to argon beam regarding time to hemostasis. Hemoglobin concentration at the 2nd day after surgery was significantly lower in the fibrin sealant group. Bile leakage was reported in $4(7 \%)$ patients in the fibrin sealant group versus $2(4 \%)$ patients in the argon beam group, which did not reach statistical significance. Overall, the frequency of adverse events did not differ between groups [20].

All the above studies mainly discussed the efficacy of fibrin sealants on hemostasis during hepatic resection. Figueras et al. [21] were the first to perform a study that primarily focused on postoperative complications. In a large single-center randomized trial, they compared fibrin sealant (Tisseel plus absorbable collagen sponge, 150 patients) with conventional hemostatic techniques in another 150 patients. Primary end points addressed bleeding complications and postoperative blood transfusion. Secondary endpoints were other resection surface-related complications and overall morbidity and mortality. There were no differences between groups in bleeding complications or postoperative transfusion rates (18 vs. $12 \%$, fibrin sealant vs. control), overall drainage volumes, days of postoperative drainage, incidence of biliary fistula (10 vs. $11 \%$ ) or postoperative morbidity (23 vs. $23 \%$ ) [21].

Similarly, Berrevoet and de Hemptinne [7] did not observe any differences in postoperative resection surfacerelated complications in a retrospective comparative cohort study between two centers. They compared the use of no sealant in their own center (Ghent, Belgium, 222 patients) with the use of a solid matrix fibrin sealant (Tachocomb, Mulheim, Germany, 173 patients) in the other center in hepatic resections performed over a period of 6 years. Patient and surgical characteristics were comparable. There were no significant differences in postoperative blood transfusion, bile leakage and reoperation for bleeding [7]. Unfortunately, detailed information has not been published on this study. 
Recently, a prospective controlled quasi-experimental study was published by Briceno et al. [22] that focused on postoperative complications after the use of fibrin sealant in liver resection. A solid matrix fibrin sealant (Tachosil, 57 patients) was compared with no sealant (58 patients). The use of fibrin sealant appeared to be effective in decreasing drainage volume, postoperative blood transfusion requirements, and moderate to severe postoperative complications. There was no difference between groups in the incidence of bile leakage. Unfortunately, patients were not randomized in this study. Instead, a 'closure' team decided whether to use fibrin sealant or to use conventional hemostatic techniques [22].

The most recent published randomized study on sealants in liver resection used a fibrin sealant glue (Tissucol, 29 patients) as a control versus the use of Plasmajet ${ }^{\circledR}$ (29 patients) on the raw surface of the liver after hepatic resection [23]. The study was designed as a pilot study. Plasmajet is a device that provides a high energy flow of ionized gas which seals small blood and lymph vessels. Instead of a positive impact of fibrin sealants, this report described a higher incidence of fluid collections requiring percutaneous drainage in the fibrin sealant group compared to the Plasmajet group. (20.6 vs. $3.4 \%$, p < 0.001). Results of this study were not described in detail but pleural effusion was also counted as a fluid collection. Abdominal fluid collections were drained in 10.3 versus 3.4\%; this difference was not significant [23].

Interestingly, two studies were published that compared two different types of fibrin sealants. Hayashibe et al. [24] published a retrospective historical cohort study comparing the use of fibrin sealant alone (fibrin glue, not further specified, 37 patients, cohort 2001-2003) with the use of the same fibrin sealant glue in combination with bio-absorbable polyglycolic acid (PGA) felt (51 patients, cohort 2003-2005). They observed more bile leakage in the group of fibrin sealant alone than in the fibrin sealant with PGA felt group (8.1 vs. $0 \%, p=0.03$ ). Their explanation for this phenomenon was that PGA felt is thought to stimulate attachment and sealing of bile ducts by fibrin glue and prevents early detachment of the fibrin glue from the cut surface of the liver [24]. Similar results were described in another retrospective historical cohort study, comparing two different fibrin sealants in split liver transplantation [25]. In the first cohort, fibrin glue was used (Tissucol, 16 patients, cohort 2003-2005); in the second, a solid matrix fibrin sealant was used (Tachosil, 16 patients, cohort 2005-2006). Bile leakage was seen in 43.7 versus $6.3 \%$ of patients, respectively $(\mathrm{p}=0.03)$ [25]. Cohorts in this last study were not completely comparable and sample sizes were low, but both studies suggest that there might be a difference between fibrin glues and solid matrix fibrin sealants.

\section{Fibrin Sealants and Prevention of Bile Leakage}

Overall, the incidence of bile leakage has not decreased over the years, and has been described in $1-14 \%$ of patients after liver resection [2, 4, 26, 27]. Risk factors for bile leakage are high-risk procedures with exposure of the major glissonian sheath $[3,4,26,28]$, resections combined with bilioenteric anastomosis $[29,30]$, size of resection plane [26], patient age [28], higher preoperative white blood cell count [28], and prolonged operation time [3, 28]. In a retrospective series of more than 600 patients, Capussotti et al. [4] showed an association between the application of fibrin sealant on the resection surface and a lower incidence of bile leakage ( $R R=0.38, p=0.046$ ). As stated before, in clinical trials this effect has not been confirmed. Only limited research has been done to investigate the efficacy of fibrin sealants in reducing the incidence of bile leakage (table 1). So far, Figueras et al. [21] are the only group that performed a well-powered study on the use of fibrin sealants in liver resections, but this study did not show a difference in the incidence of bile leakage in sealant use versus no sealant. Studies that do show a reduction in bile leakage were either of poor methodological quality or were underpowered.

Even though in clinical studies fibrin sealants do not seem to reduce bile leakage, there are some studies that indicate that fibrin sealants may have the potential to seal bile ducts. Noun et al. [15] showed that the concentration of bilirubin in the drains was significantly lower in fibrin sealant versus no sealant, suggesting a sealing effect, but they did not report on the incidence of bile leakage (table 1). In experimental studies, fibrin sealants have mainly been tested as an adjunct to suture closure of the common bile duct. Results were contradictory; some studies showed a protective effect of fibrin sealants on bile leakage from the anastomosis of the common bile duct in a dog model [31,32], whereas another study in a pig model did not [33]. Instead of using a fibrin sealant, Wise et al. [34] tested a synthetic sealant (polyethylene glycol/collagen biopolymer) in an experimental liver resection model in pigs. In all pigs, they transected the common bile duct and performed an incomplete end-to-end choledochocholedochostomy over a T-tube, leaving an anterior defect of one sixth of the circumference. In 9 pigs, sealant was applied around the circumference of the anastomo- 


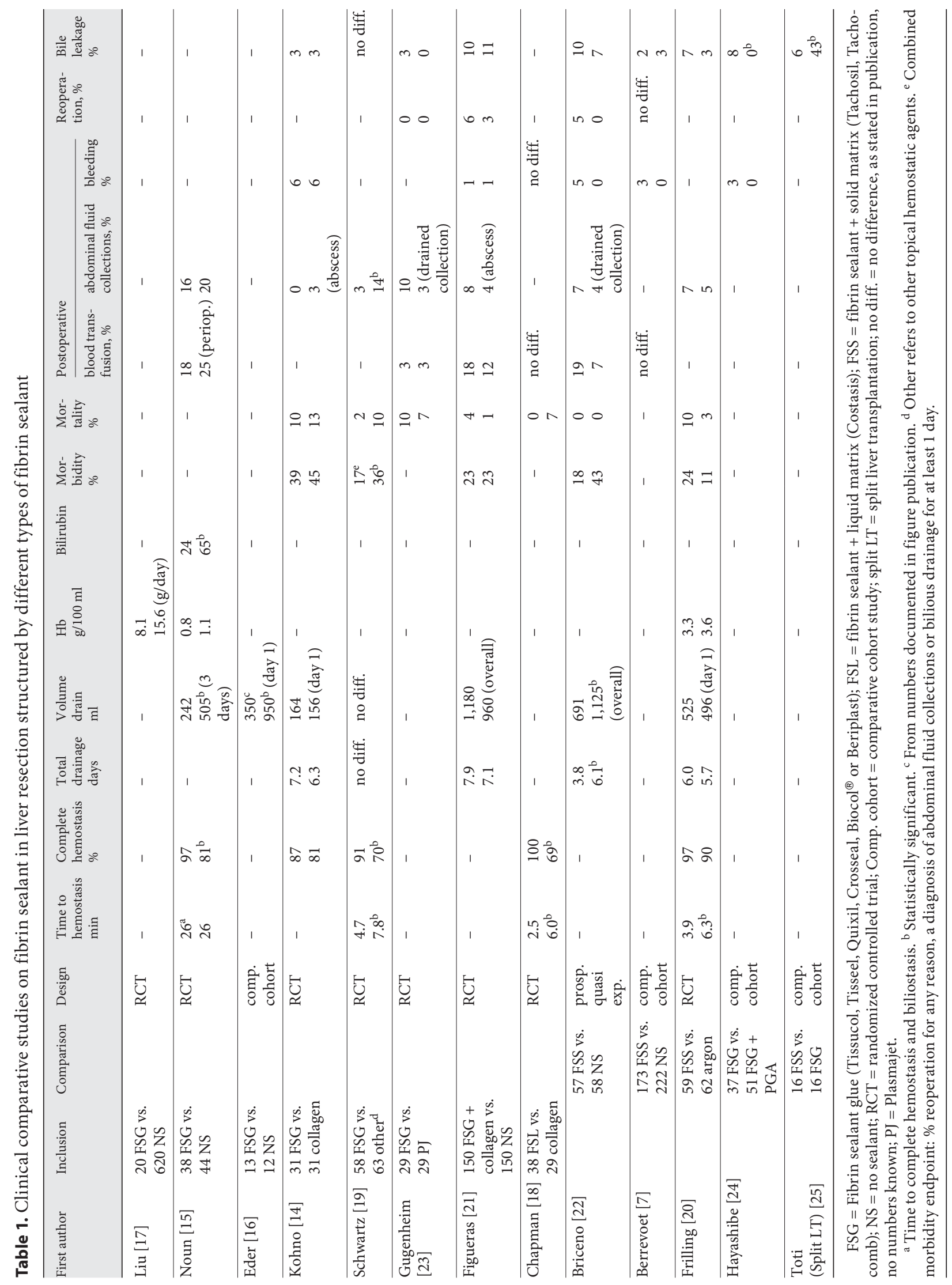


sis. Nothing was applied in the control group. Bile leakage was seen in 5 out of $9(56 \%)$ in the control group versus 1 out of $9(11 \%)$ in the sealant group $(p<0.05)$ [34]. In conclusion, use of this synthetic sealant resulted in a reduction in the incidence of bile leakage, which could not clearly be shown in other studies when fibrin sealants were used. Lack of evidence in the experimental fibrin sealant studies might also be attributable to a poor design of these studies.

Erdogan and van Gulik [35] suggested adhesive strength of the fibrin sealant to be an important factor in the prevention of bile leakage. They performed an experimental study in a partial liver resection model in pigs. They compared the use of a solid matrix fibrin sealant (Tachosil, 4 pigs) with the use of a fibrin sealant glue (Tissucol, 4 pigs) on the liver resection surface [35]. A catheter was introduced in the common bile duct. Two hours after application of the sealant, pressure in the common bile duct was increased with the use of saline. The pressure that could be resisted with the liquid fibrin sealant was significantly lower compared to solid matrix fibrin sealant. This study showed that the adhesive strength of this solid matrix sealant was better than the fibrin glue [35, 36]. Whether the adhesive strength of these solid matrix sealants is intrinsic to the product or caused by the fact that the sealant is applied to the surface by pressure has not been investigated. It has been postulated that the adhesive strength of products that can be applied with pressure are theoretically better than products that are applied without pressure, like the liquid fibrin sealants [9]. This could also be concluded from the two clinical studies by Hayashibe et al. [24] and Toti et al. [25]. Both studies compared different sealants or different combination and application of products. Again, from these studies it is not clear whether the possible differences in effect on bile leakage between fibrin sealant glues and solid matrix fibrin sealants are caused by the products themselves or by the differences in application (pressure vs. no pressure).

The stability of fibrin sealants on dissected bile ducts has not been studied in detail. The study previously discussed by Erdogan and van Gulik [35] used saline to increase pressure in the common bile duct instead of bile. Interestingly, there are indications from the literature that bile interferes with the hemostatic process, a process which is mimicked by the fibrin sealant when applied to the resection surface of the liver. In 1919, Haessler and Stebbins were the first to report on the anticoagulant effect of bile [37]. More than 50 years later, bile was found to contain fibrinolytic activity, and a protein referred to as bilokinase was isolated [38-41]. Several studies identified the presence of different fibrinolytic proteins including plasminogen, plasminogen activator inhibitor type 1 (PAI-1) and plasminogen activator (tPA) in human bile [42-44]. Although these studies did not address whether these proteins were functional, they do raise the question whether bile has a lytic effect on fibrin sealants or not.

Recently, our group investigated the effect of human bile on the stability of different fibrin sealants and plasma clots in vitro [45]. Addition of bile to fibrin sealants accelerated lysis of in vitro clotted fibrin sealants. The lysispromoting activity of bile could be partially blocked by immunodepletion of tissue-type plasminogen activator (tPA). Lytic activity was completely blocked when both tPA and lysine-binding proteins were immunodepleted, which suggests that tPA and plasminogen are responsible for the lysis-promoting effect of human bile. The lytic effect of bile could not be blocked by the addition of highdose PAI-1, and we showed that tPA in a biliary environment is unsusceptible to PAI-1 inhibition. Results of this experimental study suggest that the presence of tPA and other fibrinolytic proteins in human bile cause lysis of plasma and fibrin glues [45]. Whether these effects account for all fibrin sealants or only for the fibrin sealants tested in this study, remains to be seen.

These lytic effects of bile on fibrin sealants have not been proven in vivo, but might be an explanation why there is no evidence so far for the efficacy of fibrin sealants in reducing bile leakage after liver resection. Future studies are needed that focus on the effect of fibrin sealants on the incidence of bile leakage. We are currently awaiting the results of a Dutch multicenter randomized study on the effect of fibrin sealants in reducing resection surface-related complications (FRESCO study; controlledtrials.com: ISRCTN85205641). Future focus of bile leakage reduction may lie in the development of synthetic sealants.

In conclusion, fibrin sealants are widely used in liver surgery. Several fibrin sealant studies were performed in the field of liver surgery to analyze their efficacy on hemostasis, postoperative drain fluid production and resection surface-related complications like bile leakage, bleeding and abscess formation. In general, these studies have shown a reduced time to hemostasis when fibrin sealants were used. However, few studies have been published so far that focused on postoperative resection surface-related complications, like bile leakage, bleeding or abscess formation. Although different types of fibrin sealants showed different results, there is no strong evidence that fibrin sealants reduce the incidence of bile 
leakage after liver resections. Studies that did show a reduction in resection surface related complications were either of poor methodological quality or were underpowered. Important new evidence shows that bile contains profibrinolytic activity that causes lysis of the clot formed by the fibrin sealant at least in vitro. Future studies are needed to further analyze the lysis of different fibrin sealants (fibrin glues vs. solid matrix fibrin sealants) in vitro and in vivo by human bile. Apart from improvement of surgical techniques, a possible solution to the problem of bile leakage after liver resection may lie in the development of safe and ready to use synthetic sealants instead of fibrin sealants. Since there is no evidence on the efficacy of fibrin sealants in reducing postoperative resection surface-related complications, routine use of fibrin sealants in liver surgery cannot be recommended.

\section{References}

1 Jarnagin WR, Gonen M, Fong Y, DeMatteo RP, Ben Porat L, Little S, et al: Improvement in perioperative outcome after hepatic resection: analysis of 1,803 consecutive cases over the past decade. Ann Surg 2002;236:397406.

-2 Reed DN Jr, Vitale GC, Wrightson WR, Edwards M, McMasters K: Decreasing mortality of bile leaks after elective hepatic surgery. Am J Surg 2003;185:316-318.

-3 Yamashita Y, Hamatsu T, Rikimaru T, Tanaka S, Shirabe K, Shimada M, et al: Bile leakage after hepatic resection. Ann Surg 2001; 233:45-50.

-4 Capussotti L, Ferrero A, Vigano L, Sgotto E, Muratore A, Polastri R: Bile leakage and liver resection: where is the risk? Arch Surg 2006; 141:690-694.

-5 Boonstra EA, Molenaar IQ, Porte RJ, de Boer MT: Topical haemostatic agents in liver surgery: do we need them? HPB (Oxford) 2009; 11:306-310.

-6 Nakajima Y, Shimamura T, Kamiyama T, Matsushita M, Sato N, Todo S: Control of intraoperative bleeding during liver resection: analysis of a questionnaire sent to 231 Japanese hospitals. Surg Today 2002;32:48-52.

7 Berrevoet F, de Hemptinne B: Clinical application of topical sealants in liver surgery: does it work? Acta Chir Belg 2007;107:504507.

8 Kraus TW, Mehrabi A, Schemmer P, Kashfi A, Berberat P, Buchler MW: Scientific evidence for application of topical hemostats, tissue glues, and sealants in hepatobiliary surgery. J Am Coll Surg 2005;200:418-427.

-9 Berrevoet F, de Hemptinne B: Use of topical hemostatic agents during liver resection. Dig Surg 2007;24:288-293.

10 Mosesson MW: Fibrin polymerization and its regulatory role in hemostasis. J Lab Clin Med 1990;116:8-17.

-11 Dickneite G, Metzner H, Pfeifer T, Kroez M, Witzke G: A comparison of fibrin sealants in relation to their in vitro and in vivo properties. Thromb Res 2003;112:73-82.

12 Busuttil RW: A comparison of antifibrinolytic agents used in hemostatic fibrin sealants. J Am Coll Surg 2003;197:1021-1028.
13 Okada M, Blomback B: Factors influencing fibrin gel structure studied by flow measurement. Ann N Y Acad Sci 1983;408:233-253.

14 Kohno H, Nagasue N, Chang YC, Taniura H, Yamanoi A, Nakamura T: Comparison of topical hemostatic agents in elective hepatic resection: a clinical prospective randomized trial. World J Surg 1992;16:966-969.

15 Noun R, Elias D, Balladur P, Bismuth H, Parc $\mathrm{R}$, Lasser $\mathrm{P}$, et al: Fibrin glue effectiveness and tolerance after elective liver resection: a randomized trial. Hepatogastroenterology 1996;43:221-224.

16 Eder F, Meyer F, Nestler G, Halloul Z, Lippert $\mathrm{H}$ : Sealing of the hepatic resection area using fibrin glue reduces significant amount of postoperative drain fluid. World J Gastroenterol 2005;11:5984-5987.

17 Liu M, Lui WY: The use of fibrin adhesive for hemostasis after liver resection. Zhonghua Yi Xue Za Zhi (Taipei) 1993;51:19-22.

18 Chapman WC, Clavien PA, Fung J, Khanna A, Bonham A: Effective control of hepatic bleeding with a novel collagen-based composite combined with autologous plasma: results of a randomized controlled trial. Arch Surg 2000;135:1200-1204.

19 Schwartz M, Madariaga J, Hirose R, Shaver TR, Sher L, Chari R, et al: Comparison of a new fibrin sealant with standard topical hemostatic agents. Arch Surg 2004;139:11481154.

20 Frilling A, Stavrou GA, Mischinger HJ, de Hemptinne B, Rokkjaer M, Klempnauer J, et al: Effectiveness of a new carrier-bound fibrin sealant versus argon beamer as haemostatic agent during liver resection: a randomised prospective trial. Langenbecks Arch Surg 2005;390:114-120.

21 Figueras J, Llado L, Miro M, Ramos E, Torras J, Fabregat J, et al: Application of fibrin glue sealant after hepatectomy does not seem justified: results of a randomized study in 300 patients. Ann Surg 2007;245:536-542.

22 Briceno J, Naranjo A, Ciria R, Diaz-Nieto R, Sanchez-Hidalgo JM, Luque A, et al: A prospective study of the efficacy of clinical application of a new carrier-bound fibrin sealant after liver resection. Arch Surg 2010;145: $482-488$.
23 Gugenheim J, Bredt LC, Iannelli A: A randomized controlled trial comparing fibrin glue and PlasmaJet on the raw surface of the liver after hepatic resection. Hepatogastroenterology 2011;58:922-925.

24 Hayashibe A, Sakamoto K, Shinbo M, Makimoto S, Nakamoto T: New method for prevention of bile leakage after hepatic resection. J Surg Oncol 2006;944:57-60.

25 Toti L, Attia M, Manzia TM, Lenci I, Gunson B, Buckels JA, et al: Reduction in bile leaks following adult split liver transplant using a fibrin-collagen sponge: a pilot study. Dig Liver Dis 2010;42:205-209.

26 Nagano Y, Togo S, Tanaka K, Masui H, Endo I, Sekido H, et al: Risk factors and management of bile leakage after hepatic resection. World J Surg 2003;27:695-698.

27 van den Broek MA, van Dam RM, Malago M, Dejong $\mathrm{CH}$, van Breukelen GJ, Olde Damink SW: Feasibility of randomized controlled trials in liver surgery using surgery-related mortality or morbidity as endpoint. Br J Surg 2009;962:1005-1014.

28 Lo CM, Fan ST, Liu CL, Lai EC, Wong J: Biliary complications after hepatic resection: Risk factors, management, and outcome. Arch Surg 1998;133:156-161.

29 IJitsma AJ, Appeltans BM, de Jong KP, Porte RJ, Peeters PM, Slooff MJ: Extrahepatic bile duct resection in combination with liver resection for hilar cholangiocarcinoma: a report of 42 cases. J Gastrointest Surg 2004;8: 686-694.

30 Erdogan D, Busch OR, Gouma DJ, van Gulik TM: Prevention of biliary leakage after partial liver resection using topical hemostatic agents. Dig Surg 2007;24:294-299.

- 31 Couto J, Kroczek B, Requena R, Lerner R: Autologous fibrin glue as a sealant of the common bile duct. Surgery 1987;101:354356.

32 Kram HB, Garces MA, Klein SR, Shoemaker WC: Common bile duct anastomosis using fibrin glue. Arch Surg 1985;120:1250-1256.

- 33 Jones DB, Brewer JD, Meininger TA, Soper NJ: Sutured or fibrin-glued laparoscopic choledochojejunostomy. Surg Endosc 1995; 9:1020-1027. 
-34 Wise PE, Wudel LJ Jr, Belous AE, Allos TM, Kuhn SJ, Feurer ID, et al: Biliary reconstruction is enhanced with a collagen-polyethylene glycol sealant. Am Surg 2002;68:553561, discussion 561-562.

- 35 Erdogan D, de Graaf W, van Gulik TM: Adhesive strength of fibrinogen-coated collagen patch or liquid fibrin sealant in an experimental liver resection model in pigs. Eur Surg Res 2008;41:298-302.

-36 Erdogan D, van Gulik TM: Evolution of fibrinogen-coated collagen patch for use as a topical hemostatic agent. J Biomed Mater Res B Appl Biomater 2008;85:272-278.

-37 Haessler H, Stebbins MG: Effect of bile on the clotting time of blood. J Exp Med 1919; 29:445-449.
38 Chung SC, Kim YC, Hong SK, Lee PH: Effect of bile on the blood coagulation. Yonsei Med J 1964;5:24-28.

39 King JB: Fibrinolysis by bile. Thromb Diath Haemorrh 1972;28:299-305.

40 Oshiba S, Ariga T: Purification and characterization of the biliary plasminogen activator bilokinase. J Biol Chem 1983;258:622628.

41 Oshiba S, Ariga T: Proceedings: purification and characterization of bilokinase, a biliary plasminogen activator. Thromb Diath Haemorrh 1975;34:319.
42 Scott-Coombes DM, Whawell SA, Havranek EG, Thompson JN: Fibrinolysis and the biliary tree. Gut 1997;40:92-94.

43 Gil D, Michalski A, Kondera-Anasz Z, Gil B, Starzewski J, Gonciarz Z: Do fibrinolytic proteins of human bile derive exclusively from gall bladder? Med Sci Monit 2001; 7(suppl 1):262-263.

44 Kondera-Anasz Z, Michalski A, Gil D, Gil B, Starzewski J, Gonciarz Z: Accuracy of t-PA, u-PA, PAI-1 and PAI-2 estimation in human bile by ELISA kits. Med Sci Monit 2000;6: 616-617.

45 Boonstra EA, Adelmeijer J, Verkade HJ, de Boer MT, Porte RJ, Lisman T: Fibrinolytic proteins in human bile accelerate lysis of plasma clots and induce breakdown of fibrin sealants. Ann Surg, in press. 